\title{
From tameness to wariness: chemical recognition of snake predators by lizards in a Mediterranean island
}

\author{
Abraham Mencía ${ }^{1}$, Zaida Ortega ${ }^{\text {Corresp., }}{ }^{1}$, Valentín Pérez-Mellado ${ }^{1}$ \\ ${ }^{1}$ Department of Animal Biology, University of Salamanca, Salamanca, Salamanca, Spain \\ Corresponding Author: Zaida Ortega \\ Email address: zaidaortega@usal.es
}

Antipredatory defenses are maintained when benefit exceeds cost. A weak predation pressure may lead insular lizards to tameness. Podarcis lilfordi exhibits a high degree of insular tameness, which may explain its extinction from the main island of Menorca when humans introduced predators. There are three species of lizards in Menorca: the native $P$. lilfordi, only on the surrounding islets, and two introduced lizards in the main island, Scelarcis perspicillata and Podarcis siculus. Besides, there are three species of snakes, all introduced: one non-saurophagous (Natrix maura), one potentially non-saurophagous (Rhinechis scalaris) and one saurophagous (Macroprotodon mauritanicus). We studied the reaction to snake chemical cues in five populations: (1) P. lilfordi of Colom, (2) P. lilfordi of Aire, (3) P. lilfordi of Binicodrell, (4) S. perspicillata, and (5) P. siculus, ordered by increasing level of predation pressure. The three snakes are present in the main island, while only $R$. scalaris is present in Colom islet, Aire and Binicodrell being snake-free islets. We aimed to assess the relationship between predation pressure and the degree of insular tameness regarding scent recognition. We hypothesized that $P$. lilfordi should show the highest degree of tameness, $S$. perspicillata should show intermediate responses, and $P$. siculus should show the highest wariness. Results are clear: neither $P$. lilfordi nor $S$. perspicillata recognize any of the snakes, while $P$. siculus recognizes the scent of $M$. mauritanicus and reacts to it with typical well-defined antipredatory behaviours as tail waving and slow motion. This results rise questions about the loss of chemical recognition of predators during island tameness and its related costs and benefits for lizards of insular habitats. In addition, this highlights the necessity for strong conservation measures to avoid the introduction of alien predators. 
1 Title: From tameness to wariness: chemical recognition of snake predators by lizards in a 2 Mediterranean island

3 Authors: Abraham Mencía ${ }^{a}$, Zaida Ortega ${ }^{a}$ \& Valentín Pérez-Mellado ${ }^{a}$

4 aDepartment of Animal Biology, University of Salamanca, Campus Miguel de Unamuno, 37007, 5 Salamanca, Spain.

6 Abraham Mencía and Zaida Ortega must appear as co-first authors, with the same order of authors 7 reported here.

8 Corresponding author: Zaida Ortega. Postal address: Department of Animal Biology, 9 University of Salamanca, Campus Miguel de Unamuno, s/n, 37007, Salamanca, Spain. Phone 10 number: 0034 627968559. E-mail address: zaidaortega@,usal.es 


\section{Abstract}

12 Antipredatory defenses are maintained when benefit exceeds cost. A weak predation 13 pressure may lead insular lizards to tameness. Podarcis lilfordi exhibits a high degree of insular 14 tameness, which may explain its extinction from the main island of Menorca when humans introduced predators. There are three species of lizards in Menorca: the native P. lilfordi, only on

16 the surrounding islets, and two introduced lizards in the main island, Scelarcis perspicillata and 17 Podarcis siculus. Besides, there are three species of snakes, all introduced: one non-saurophagous 18 (Natrix maura), one potentially non-saurophagous (Rhinechis scalaris) and one saurophagous 19 (Macroprotodon mauritanicus). We studied the reaction to snake chemical cues in five populations: (1) P. lilfordi of Colom, (2) P. lilfordi of Aire, (3) P. lilfordi of Binicodrell, (4) $S$. perspicillata, and (5) P. siculus, ordered by increasing level of predation pressure. The three snakes are present in the main island, while only R. scalaris is present in Colom islet, Aire and Binicodrell being snake-free islets. We aimed to assess the relationship between predation pressure and the degree of insular tameness regarding scent recognition. We hypothesized that $P$. lilfordi should show the highest degree of tameness, $S$. perspicillata should show intermediate responses, and $P$. siculus should show the highest wariness. Results are clear: neither P. lilfordi nor S. perspicillata recognize any of the snakes, while $P$. siculus recognizes the scent of $M$. mauritanicus and reacts to it with typical well-defined antipredatory behaviours as tail waving and slow motion. This results rise questions about the loss of chemical recognition of predators during island tameness and its related costs and benefits for lizards of insular habitats. In addition, this highlights the necessity for strong conservation measures to avoid the introduction of alien predators. 


\section{INTRODUCTION}

Predation is one of the main evolutionary forces for animals. Animals whose physiological, morphological or behavioural defenses allow them to avoid predators will enhance survival (Endler 1986; Lima and Dill 1990). The hunting mechanisms of predators and the defenses of preys usually coevolve in a cost-benefit model (Greene 1988; Lima and Dill 1990; Vermeij 1994; Sih et al. 2010). Thus, some antipredatory adaptations may be costly under low predation pressure, reducing opportunities for feeding or mating (Relyea 2002; Brönmark et al. 2011). Insular populations often experience much weaker predation pressures than continental animals, which results in the evolution of tameness, a reduction of antipredatory responses (Darwin 1839; Curio 1976; Blumstein and Daniel 2005). Thus, tameness is a reduction of different behavioural responses and reflects the relaxation of defensive mechanisms. Insular tameness arises when the cost of maintaining the physiological, morphological or behavioural antipredator defences exceeds the benefits in predator-free environments (McNab 1994; Van Damme and Castilla 1996; Magurran 1999; Blumstein and Daniel 2005; Rödl et al. 2007). Then, the introduction of nonnative predators on islands may give rise to novel predator-prey interactions (Strauss et al. 2006; Sih et al. 2010; Simberloff et al 2013). Occasionally, naïve native prey may be unable to recognize predators or to respond with sufficient effectiveness (Banks and Dickman 2007; Kovacs et al. 2012). Furthermore, the inability of naïve prey to recognize and avoid alien predators may improve the ability of alien predator to hunt on these naïve preys (Sih et al. 2010). If alien predators had coevolved with similar preys as the naïve ones in their original habitats, the situation could be more dramatic and even result in the extinction of the naïve prey population (Sih et al. 2010; Blackburn et al. 2004).

As it relates to biological invasions, the case of the reptiles of the Balearic Islands (Spain; Fig1) is probably the most typical within the Mediterranean basin, and maybe one of the more concerning worldwide (Silva-Rocha et al. 2015). Nowadays, there are nineteen alien reptiles and only two native, the Balearic lizard (Podarcis lilfordi) and the Ibiza wall lizard (Podarcis pityusensis; Silva-Rocha et al. 2015). We focus the study on Menorca (Fig1), where it is probable that the introduction of alien predators by humans in ancient times led to extinction of the Balearic lizard on the main island (Pérez-Mellado 2009; Cooper and Pérez-Mellado 2012). Thus, the sole native reptile of Menorca, the Balearic lizard, only survives today in the surrounding islets, while 
62 other introduced lizards have been able to live in the main island of Menorca (Pérez-Mellado 2009; 63 Salvador 2014a). The non-native lizards are the Italian wall lizard, Podarcis siculus, with well-

64

65

66 established populations all over the island (Salvador 2014b), and the Moroccan rock lizard, Scelarcis perspicillata, with some restricted populations (Perera 2002; Perera 2014). There are also three species of snakes in Menorca, all of them introduced by humans: the viperine snake, Natrix maura, the false smooth snake, Macroprotodon mauritanicus, and the ladder snake, Rhinechis scalaris. Islets on which the Balearic lizard is found are snake-free except for the islet of Colom, on where, there is a population of ladder snakes whose interactions with $P$. lilfordi are unknown (Mejías and Amengual 2000).

It is well-known that the Balearic lizard has evolved insular tameness, which is probably extreme and irreversible (Pérez-Mellado et al. 1997; Cooper et al. 2004; Cooper et al. 2009; Cooper and Pérez-Mellado 2012). Taking advantage of this unique situation, we aim to deepen in the knowledge of insular tameness, studying the ability of lizards to recognize the scent of predatory snakes. It is possible, as with escape behaviour (Cooper et al. 2009), that the intensity of antipredatory reactions of lizards to the scent of snakes is related to predation pressure. Therefore, we experimentally assessed the level of response of the three lacertid lizards of Menorca to the chemical cues of their potential predatory snakes. Thus, we hypothesized that $P$. lilfordi might have lost the ability to recognize the scents of potential predators, being the tamest population. Meanwhile, S. perspicillata, which experiences a middle level of snakes' predation pressure, is expected to recognize and react to the scents of the saurophagous snake, at least to some level. Finally, $P$. siculus would be the wariest population, and fully recognize the chemical cues of the predator snake and react with antipredatory behaviours, circumstance that would help this species to colonize and extensively inhabit the main island of Menorca. Thus, if the response to chemical cues of predators reflects the predation pressure level of each population, we would expect the following order of intensity in the reactions of lizards: P. lilfordi Colom $<P$. lilfordi Aire $<P$. lilfordi Binicodrell $<$ S. perspicillata $<$ P. siculus.

\section{METHODS}

\section{Study system}


We studied chemoreception of the three species of lizards of Menorca (Balearic Islands,

91 Fig1): one is the native lizard of the island (P. lilfordi) and the other two are introduced species $(S$. 92 perspicillata and $P$. siculus).

93 The Balearic lizard, Podarcis lilfordi (Günther 1874) is endemic to Menorca, Mallorca and 94 the Cabrera archipelago (Balearic Islands, Spain). We studied three subspecies: (1) P. lilfordi 95 brauni from Colom island, which coexists with Rhinechis scalaris, (2) P. lilfordi lilfordi from the 96 snake-free island of Aire, and (3) P. lilfordi codrellensis from the snake-free island of Binicodrell. 97 The three islands are close to the coast of Menorca, and show different levels of predation pressure 98 (considering all types of predators): Colom < Aire < Binicodrell (Cooper and Pérez-Mellado 99 2012).

The Moroccan rock lizard, Scelarcis perspicillata (Duméril and Bribon 1839), is originally from the mountainous region of Morocco and Algeria, with introduced populations in Menorca (Perera 2014). The studied population lives in the Pedreres de S'Hostal or Lithica, a limestone quarry with high walls (Perera 2002; Vitt et al. 2002). The population of the Moroccan rock lizard living in Menorca probably belongs to the subspecies S. perspicillata perspicillata (Perera et al. 2007).

The Italian wall lizard, Podarcis siculus (Rafinesque-Schmalz 1810), is originally from Italy (continental Italy, Sardinia, Sicily and several coastal islets), Corsica (France) and the east coast of the Adriatic Sea (Salvador 2014b). However, P. siculus has been introduced to many Mediterranean countries and the United States (Salvador 2014b). Here we studied the lizard population of Menorca (Balearic Islands, Spain), probably introduced from Sicily and/or Sardinia

111 (Silva-Rocha et al. 2012).

Regarding snakes, we used the three species present in Menorca, all of them introduced by

113 humans (Silva-Rocha et al. 2015): The first one is Macroprotodon mauritanicus, which inhabits

114 the main island of Menorca and is known to predate on lizards (Pleguezuelos 2014). The second 115 one is Rhinechis scalaris, which inhabits the main island of Menorca and the islet of Colom, and 116 is a generalist that predates on endotherms, being proposed as a potential predator of lizards 117 (Pleguezuelos 1998). The third snake is Natrix maura, which inhabits the main island of Menorca 118 and feeds on aquatic prey, and certainly not a predator of lizards (Santos 2014). 


\section{Experimental Design}

120 We conducted five experiments of discrimination of scents by lizards during the summer 121 of 2013 in Menorca (Spain). We captured 24 lizards (12 males and 12 females) of each population 122 (24 X 5 = 120): (1) P. lilfordi of Colom (mean SVL \pm SE: males $=72.42 \pm 0.95 \mathrm{~mm}$, females $=$ $12366.96 \pm 0.71 \mathrm{~mm})$, (2) P. lilfordi of Aire (males $=75.50 \pm 1.12 \mathrm{~mm}$, females $=69.12 \pm 0.83 \mathrm{~mm})$, 124 (3) P. lilfordi of Binicodrell (males $=69.54 \pm 0.41 \mathrm{~mm}$, females $=65.85 \pm 0.34 \mathrm{~mm}$ ), (4) P. siculus, $125($ males $=71.00 \pm 1.09 \mathrm{~mm}$, females $=68.81 \pm 0.88 \mathrm{~mm})$ and $(5) S$. perspicillata $($ males $=51.08 \pm$ $1260.45 \mathrm{~mm}$, females $=48.25 \pm 0.52 \mathrm{~mm}$ ). We captured all lizards by noosing and immediately placed 127 them into individual cloth bags inside individual terraria for transport to the laboratory for each 128 experiment. Snakes were captured in Menorca, and were transported in a different vehicle than 129 lizards in order to avoid any odour mixture. All experiments were conducted in the same laboratory 130 in Es Castell (Menorca, Spain). There, we kept lizards inside individual terraria (40 x $25 \times 30 \mathrm{~cm})$ 131 in a maintenance room, with a substrate of artificial grass. We fed lizards daily with crickets and

132 Tenebrio molitor larvae, and provided them water ad libitum. We housed snakes in a different 133 maintenance room, also inside individual terraria $(50 \times 30 \times 30 \mathrm{~cm})$ with a substrate of artificial 134 grass and water ad libitum.

135 Our experimental protocol is similar to the one used in Mencía et al. (2016). It consists in 136 quantifying the behaviour of lizards in terraria with four different scent treatments: 'odourless 137 control', 'Natrix', 'Rhinechis', and 'Macroprotodon'. The treatment of Natrix is used as a pungent 138 odour (see Mencía et al. 2016). We used the same protocol and treatments for the five experiments.

139 We placed absorbent paper on the floor of every experimental terrarium $(60 \times 40 \times 40 \mathrm{~cm})$ 140 in order to absorb the odour of each treatment. Then, we used the different snakes as odour-donors 141 to impregnate the absorbent paper with their scents, except for the 'odourless control' terrarium. 142 These odour-donors were adult individuals of each species. The snakes were placed into the 143 corresponding terrarium $24 \mathrm{~h}$ before the beginning of the experiment, and were placed inside them 144 once again during the extra time between trials of other treatments, closing the occlusive plastic 145 cover of the terrarium to avoid odour loss. Each snake was removed from its terrarium two minutes 146 before an experiment trial and re-introduced there after the trial. 
Each lizard was subjected once to each treatment following a random order of 148 permutations, resulting in 480 trials (24 lizards x 4 treatments x 5 experiments). Each lizard was tested once a day within their normal activity period (0800 to $1700 \mathrm{GMT})$. The experimental room was dark and only the terrarium was illuminated by a $75 \mathrm{~W}$ bulb $50 \mathrm{~cm}$ above it, providing homogeneous lighting. We maintained a homogeneous constant temperature of $30^{\circ} \mathrm{C}$ in the

152 experimental room in order to avoid possible variations in the behaviour of lizards due to 153 temperature. We drew six equal sectors (in two rows by three columns) in the transparent surface 154 of each terrarium in order to count the number of times that lizards moved among sectors. Each 155 trial was begun by introducing the lizard into the experimental terrarium, closing the terrarium 156 with the occlusive transparent cover in order to avoid scent loss, and beginning to record its 157 behaviour with a digital recorder for 15 minutes. Two observers were placed in front of the 158 terrarium, opposite to each other: one observer recorded the behavioural variables with binoculars 159 and the other recorded the number of movements and changes among the sectors of the terrarium. 160 It was not possible to record data blindly because terraria were clearly labelled to avoid mistakes. 161 Additionally, snakes were re-introduced into their terraria after trials. In any case, bias should be

162 low since lizards' behaviours registered by the two observers. All specimens remained healthy 163 throughout the study period and we did not detect any signs of stress. Once we finished each of 164 the five experiments, we released all lizards and snakes at their capture sites.

All experiments were performed under the license of the Balear Government (Govern de les Illes Balears, permit CEP 35/2013) and were conducted in compliance with all ethical standards and procedures of the University of Salamanca (Spain).

\section{Behavioural Variables}

We recorded 16 behavioural variables: (1) 'Walk latency': time until the first 'walk' movement, (2) 'Walk': lizards walk normally, as moving in the wild, (3) 'Change among sectors':

171 lizards move between the six predefined sectors of the experimental terrarium, (4) 'Slow': lizards 172 walk slowly and with stalking or scattered movements (Thoen et al. 1986; Mencía et al. 2016), (5) 173 'TF latency': time until the first TF (tongue-flick), (6) 'TF': lizards extrude the tongue and quickly 174 retract it into the mouth, (7) 'Snout': lizards tap the wall of the terrarium with the snout, (8) 175 'Rubbing': lizards rub the head against the walls of the terrarium, (9) 'Stand and scratching': 176 lizards stand up against the wall of the terrarium and scratch with the forelegs, (10) 'Head bob': 
177 lizards shake the head up and down, (11) 'Head raise': lizards raise the head with the forelimbs

178 straightened, (12) 'Tail waving': lizards wave the tail in a horizontal plane, (13) 'Foot shake':

179 lizards move the forelimbs rapidly up and down, (14) 'Walk time': total amount of time that lizards

180 move normally, (15) 'Slow time': total amount of time that lizards move in slow motion, and (16)

181 'No move': total amount of time that lizards stay immobile. The variables were quantified as

182 frequencies, except for 'Walk latency', 'TF latency', 'Walk time', 'Slow time', and 'No move',

183 which were quantified as duration measured in seconds. We started to record the behaviour of each

184 lizard 5 seconds after placing it in the centre of the experimental terrarium.

\section{Data Analysis}

186

We conducted all analyses on R, version 3.1.3 (R Core Team 2015). Because neither the 187 original nor log-transformed data met the requirements of parametric statistics, we analysed the data with non-parametric tests. For each experiment, we used the repeated measures Friedman's test to assess possible differences in the behavioural variables among treatments. That is, we conducted a Friedman's test on each variable of each experiment with lizard as subject and treatment as grouping factor. When Friedman's test was significant, we performed post-hoc multiple comparisons for Friedman's test in order to locate the differences between treatments (Giraudoux 2012).

\section{RESULTS}

Within each studied population, results were similar for males and females on each behavioural variable (Mann-Whitney's U test, $\mathrm{P}>0.05$ in all cases), so we pooled data of both sexes within each experiment.

There were no significant differences for any variable in the three studied populations of the Balearic lizard (Table 1, Table 2, and Table 3). Thus, P. lilfordi lizards did not recognize the odour of the potential predatory snakes of Menorca. There were no significant differences between the four treatments for all variables observed in the Moroccan rock lizard either (Table 4). Therefore, S. perspicillata lizards did not recognize the odour of the potential snake predators of 203 Menorca.

However, we found significant differences for all behavioural variables in the Italian wall 
206

207

208

209

210

211

212

213

214

215

216

217

218

219

220

221

222

223

224

225

226

227

228

229

230

231

232

233

234

treatment of Macroprotodon than for the rest, being similar for Rhinechis, Natrix and the odourless control (Fig2). In addition, the time moving normally, 'walk time', was significantly lower for the treatment of Macroprotodon than for the other scents, being similar between Rhinechis, Natrix and the odourless control (Fig3). Similar results for other variables confirmed that P. siculus lizards recognized the scent of the predatory snake $M$. mauritanicus, and reacted with antipredatory behaviours, while results indicate that they did not recognize $R$. scalaris as a predator (Table 6).

\section{DISCUSSION}

The results of the native lizard, P. lilfordi, were conclusive. The three studied populations behaved similarly with the scent of potential predatory snakes and with Natrix and with the odourless control, regardless of the predation pressure level of the population. Therefore, two explanations arise. One is that the three studied populations of $P$. lilfordi have lost the ability to recognize potential snake predator by their scents. The other possible explanation is that the capacity to react to the scent of predators with antipredatory behaviours is a secondary adaptation, and P. lilfordi never had this ability, even when it was crucial for their survival with the introduction of alien predators, to the point that they eventually disappeared from the main island.

The results of non-native lizards living on the main island of Menorca were unexpected. The first one, S. perspicillata, also lacked the ability to recognize scents of snakes, despite sharing its entire distributional range of Menorca with the two snakes, $R$. scalaris and M. mauritanicus. The other non-native lizard, P. siculus, showed opposite results, recognizing the scent of the potential predatory snake (M. mauritanicus) and responding with clear antipredatory behaviours, such as moving in slow motion and waving the tail. Rhinechis scalaris did not elicit a response in any of the three species of Menorca, reinforcing the previous observations that this snake does not predate on lizards (Proschowsky 1930; Valverde 1967).

We proved that the Balearic lizard, P. lilfordi, does not recognize scents of predatory snakes, regardless of the predation pressure of the population (Binicorell $>$ Aire $>$ Colom; Cooper and Pérez-Mellado 2012). These results reinforce the strong island tameness to which this lacertid lizard has evolved in the absent of predators (Perez-Mellado et al. 1997; Cooper et al. 2009). The Balearic lizard shows a reduced ability for tail autotomy in comparison with continental Podarcis and even with its sister species, $P$. pityusensis (Cooper et al. 2004). Independence of tail autotomy 
235 from predation pressure in $P$. lilfordi suggests that the lack of most antipredatory responses due to 236 island tameness may be fixed for this species, contrarily to what happens in P. pityusensis (Cooper 237 and Pérez-Mellado 2012). The difference in insular tameness for the two sister species would be 238 attributable to the background risk level of predation that both species have experienced along 239 their evolutionary history since they got separated, more than 2 Ma (Brown et al. 2008; Cooper 240 and Pérez-Mellado 2012). Podarcis lilfordi would have evolved with a very relaxed predation 241 pressure, free of terrestrial predators and with few birds of prey in Menorca and Mallorca, while $242 P$. pityusensis would have evolved under a greater predation pressure in Ibiza and Formentera 243 (Cooper and Pérez-Mellado 2012). This circumstance would lead the Balearic lizard be so tame 244 that it would have lost the ability to avoid alien predators once humans introduced them to 245 Menorca, more than 5000 years ago, becoming extinct on the main island and only surviving on 246 the surrounding islets, while P. pityusensis survived the invasive predators (Pérez-Mellado 2009; 247 Cooper and Pérez-Mellado 2012).

The Moroccan rock lizard, Scelarcis perspicillata was introduced in Menorca from the North of Africa, probably at various times from the XII century forward (Pérez-Mellado 2009; Perera 2014). Although it lives in other areas on the main island of Menorca, its most dense population lives in the limestone quarry of Lithica (Perera 2002; Perera 2014). Predation of $S$. perspicillata by M. mauritanicus was cited in the studied area (Vitt et al. 2002). Even though, Moroccan rock lizards lack the ability to recognize the scent of the potential predatory snake, it is possible that living within the vertical walls of Lithica would make it difficult for snake predators to access, reducing the predation pressure (Vitt et al. 2002; Pérez-Mellado 2009). In fact, there would be a benefit regarding predators' avoidance for Moroccan rock lizards living in high perches (mean perch height $78.54 \mathrm{~cm}$, Ortega et al. 2016), which would entail higher costs than ground habitats regarding the availability of trophic resources (Vitt et al. 2002). It is possible that Moroccan lizards had experienced a reduction of their antipredatory defenses since their arrival to Menorca. In any case, the future study of the African populations that coexists with predatory snakes will reveal whether these lizards have also experienced island tameness or, on the contrary, they never had the ability to recognize scents of predators. 
265 tameness evolves regarding predator recognition?, (3) is there a relationship between predation 266 pressure level and the rate of loss of antipredatory behaviour?, and (4) under what circumstances 267 can island tameness become irreversible?. These questions and many more are still unanswered 268 about the loss of antipredatory adaptations and its causes and implications for native animals under 269 invasions. It is probable that the rate of loss of any antipredatory defense would be related to its 270 cost in a predator-free environment (Van Damme and Castilla 1996; Blumstein and Daniel 2005; 271 Rödl et al. 2007). This would be the situation in islands with scarce trophic resources, as the 272 surrounding islets of Menorca for $P$. lilfordi or the vertical rock surfaces of Lithica for $S$. 273 perspicilla. It is hypothesized that the loss of wariness would lead lizards to develop the time274 required trophic behaviours that $P$. lilfordi does in islets as Aire, sucking the nectar of flowers in a highly exposed way (Cooper and Pérez-Mellado 2004; Pérez-Cembranos et al. 2013).

The other non-native lizard of Menorca, the Italian wall lizard, P. siculus, has the ability to recognize the chemical cues of M. mauritanicus and respond with antipredatory behaviours. These antipredatory responses include behaviours that would avoid predator detection, such as, walking in slow motion, others that suggest vigilance, such as, raising the head, and others that would distract attention from vital parts of the body, such as, tail vibration (Avery 1991; Thoen et al. 1986; Mencía et al. 2016). Italian wall lizards do not recognize $R$. scalaris as a predatory snake, which reinforces the evidences that the ladder snake does not predate on lizards. The extraordinary effectiveness of $P$. siculus clearly detecting the predatory snake and ignoring other non-dangerous snakes would be related to the great adaptability of this species to different environments, which would be related to its good colonizing capacity (Silva-Rocha et al. 2014). Italian wall lizards recognize chemical cues of the predatory snake Hierophis viridiflavus in Corsica, and react with similar antipredatory responses, which include slow motion and tail vibration (Van Damme and Quick 2001). In addition, $P$. siculus of Corsica modifies the use of microhabitats in the presence of snake scent (Van Damme and Quick 2001). Nonetheless, these adaptations would be extraordinarily flexible in the Italian wall lizard, as illustrated with the evolution of insular tameness only 30 years after the introduction of a population of $P$. siculus in a predator-free islet of Croatia (Vervust et al. 2007). In fact, the fast phenotypic evolution of the Italian wall lizards may be related to their remarkable ability to colonize new environments (Vervust et al. 2007).

\section{CONCLUSIONS}


Our study shows that the native lizard, $P$. lilfordi, lacks the ability to recognize potential

296

297

298

299

300

301

302

303

304

305

306

307

308

309

310

311

312

\section{3}

314

315

316 snake predator by their scents. This lack of response was similar for the three studied populations, regardless of the predation pressure and the presence or absence of snakes. One species of alien lizard, S. perspicillata, also lacked this skill even if the population coexists with $R$. scalaris and M. mauritanicus. The possible reason for the lack of response of this lizard is related to their living within vertical walls, where snakes have difficult access. The other introduced lizard, P. siculus, recognizes the chemical cues of the potential predatory snake (M. mauritanicus) and responds to them with typical antipredatory behaviours. Regarding the ladder snake, $R$. scalaris, it did not elicit a response in any of the three lizards, which supports the idea that it does not predate on lizards. Our results rise questions about the loss of chemical recognition of predators during island tameness and its related costs and benefits for lizards of insular habitats. In any case, the extreme insular tameness of $P$. lilfordi invites to further research on the evolution of antipredatory defenses in lizards and strong conservation measures to avoid invasion of their habitats by alien predators.

\section{Acknowledgments}

We thank Mary Trini Mencía and Joseph McIntyre for linguistic revision, and Mario Garrido, Ana Pérez-Cembranos, Gonzalo Rodríguez and Alicia León for assistance capturing lizards and support during writing. Finally, we thank Elisa Soteras for kindly housing us during part of the fieldwork.

\section{REFERENCES}

Avery RA (1991) Temporal dynamics of a vigilance posture in the ruin lizard Podarcis siculus. Amphibia-Reptilia 12:352-356. doi: 10.1163/156853891X00509

Banks PB, Dickman CR (2007) Alien predation and the effects of multiple levels of prey naiveté. Trends Ecol Evol 22:229-230. doi: http://dx.doi.org/10.1016/j.tree.2007.02.006

Blackburn TM, Cassey P, Duncan RP, Evans KL, Gaston KJ (2004) Avian extinction and mammalian introductions on oceanic islands. Science 305:1955-1958. doi: 10.1126/science. 1101617

Blumstein DT, Daniel JC (2005) The loss of anti-predator behaviour following isolation on islands. P Roy Soc Lond B Bio 272:1663-1668. doi: 10.1098/rspb.2005.3147 
323 Brönmark C, Lakowitz T, Hollander J (2011) Predator-induced morphological plasticity across

324

325

326

327

328

329

330

331

332

333

334

335

336

337

338

339

340

341

342

343

344

345

346

347

348

349

local populations of a freshwater snail. Plos One 6:e21773. doi: http://dx.doi.org/10.1371/journal.pone.0021773

Brown RP, Terrasa B, Pérez-Mellado V, Castro JA, Hoskisson PA, Picornell A, Ramon MM (2008) Bayesian estimation of post-Messinian divergence times in Balearic Island lizards. Molec Phylogenet Evol 48:350-358. doi: http://dx.doi.org/10.1016/j.ympev.2008.04.013 Cooper WE, Hawlena D, Pérez-Mellado V (2009) Interactive effect of starting distance and approach speed on escape behavior challenges theory. Behav Ecol 20:542-546. doi: 10.1093/beheco/arp029

Cooper WE, Peréz-Mellado V (2004) Tradeoffs between escape behavior and foraging opportunity by the Balearic lizard (Podarcis lilfordi). Herpetologica 60:321-324. doi: http://dx.doi.org/10.1655/04-20

Cooper WE, Pérez-Mellado V (2012) Historical influence of predation pressure on escape by Podarcis lizards in the Balearic Islands. Biol J Linn Soc 107:254-268. doi: 10.1111/j.10958312.2012.01933.x

Cooper WE, Pérez-Mellado V, Vitt LJ (2004) Ease and effectiveness of costly autotomy vary with predation intensity among lizard populations. J Zool 262:243-255. doi: $10.1017 / \mathrm{S} 095283690300462 \mathrm{X}$

Curio E (1976) The ethology of predation. Springer-Verlag, Berlin

Darwin C (1839) Journal of researches into the geology and natural history of the various countries visited by H. M. S. Beagle, under the command of Captain Fitzroy, R. N. from 1832-1836. Henry Colburn, London

Endler JA (1986) Defense against predators. In: Feder ME, Lauder GV (eds) Predator-prey relationships: perspectives and approaches from the study of lower vertebrates. University of Chicago Press, Chicago, pp 169-202

Giraudoux P (2012) pgirmess: Data analysis in ecology. R package version 1.5.6. http://CRAN.Rproject.org/package=pgirmess. Accessed 7 June 2016 
350 Greene HW (1988) Antipredator mechanisms in reptiles. In: Gans C, Huey RB (eds) Biology of

351

352

353

354

355

356

357

358

359

360

361

362

363

364

365

366

367

368

369

370

371

372

373

374

375

Reptilia, Vol. 16. Ecology B: Defense and Life History, Alan R Liss, New York, pp 1-152

Kovacs EK, Crowther MS, Webb JK, Dickman CR (2012) Population and behavioural responses of native prey to alien predation. Oecologia 168:947-957. doi: 10.1007/s00442-011-21689

Lima SL, Dill LM (1990) Behavioral decisions made under the risk of predation: a review and prospectus. Can J Zool 68:619-640. doi: 10.1139/z90-092

Magurran AE (1999) The causes and consequences of geographic variation in antipredator behaviour. In: Foster SA, Endler JA (eds) Geographic variation in behavior: perspectives on evolutionary mechanisms, Oxford University Press, Oxford, pp 139-163

McNab BK (1994) Energy conservation and the evolution of flightlessness in birds. Am Nat 144:628-642.

Mejías R, Amengual J (2000) Llibre vermell dels vertebrats de les Balears. Majorca: Servei de Protección d'Espècies, Direcció General de Biodiversitat, Conselleria de Medi Ambient, Palma

Mencía A, Ortega Z, Pérez-Mellado V (2016) Chemical discrimination of sympatric snakes by the mountain lizard Iberolacerta galani (Squamata: Lacertidae). Herpetol J 26:151-157.

Ortega Z, Mencía A, Pérez-Mellado V (2016) Sexual differences in behavioral thermoregulation of the lizard Scelarcis perspicillata. J Therm Biol 61:44-49. doi: http://dx.doi.org/10.1016/j.jtherbio.2016.08.006

Perera A (2002) Lacerta perspicillata Duméril y Bibron, 1839. Lagartija de Marruecos. In: Pleguezuelos JM, Márquez R, Lizana M (eds) Atlas y libro Rojo de los Anfibios y Reptiles de España, 2nd edn. DGCN-AHE, Madrid, pp 231-232

Perera A (2014) Scelarcis perspicillata (Duméril y Bibron, 1839). In: Salvador A (coord) Reptiles, $2^{\mathrm{a}}$ edición revisada y aumentada. Fauna Ibérica, vol. 10, Museo Nacional de Ciencias Naturales, CSIC, Madrid, pp 612-617 
376 Perera A, Vasconcelos R, Harris DJ, Brown RP, Carretero MA, Pérez-Mellado V (2007) Complex

377

378

379

380

381

382

383

384

385

386

387

388

389

390

391

392

393

394

395

396

397

398

399

400 patterns of morphological and mtDNA variation in Lacerta perspicillata (Reptilia; Lacertidae). Biol J Linn Soc 90:479-490. doi: 10.1111/j.1095-8312.2007.00736.x

Pérez-Cembranos A, Pérez-Mellado V, Cooper WE (2013) Predation risk and opportunity cost of fleeing while foraging on plants influence escape decisions of an insular lizard. Ethology 119:522-530. doi: 10.1111/eth.12092

Pérez-Mellado V (2009) Les sargantanes de les Balears. Quaderns de Natura de les Balears. Edicions Documenta Balear, Palma, Majorca

Perez-Mellado V, Corti C, Lo Cascio P (1997) Tail autotomy and extinction in Mediterranean lizards. A preliminary study of continental and insular populations. J Zool 243:533-541. doi: 10.1111/j.1469-7998.1997.tb02799.x

Pleguezuelos JM (1998) Elaphe scalaris. In: Salvador A (coord) Fauna Ibérica, Vol. 10, Reptiles, Museo Nacional de Ciencias Naturales, CSIC, Madrid, pp 390-407

Pleguezuelos JM (2014) Macroprotodon mauritanicus Guichenot, 1850. In: Salvador A (coord) Reptiles, $2^{\mathrm{a}}$ edición revisada y aumentada. Fauna Ibérica, vol. 10, Museo Nacional de Ciencias Naturales, CSIC, Madrid, pp 769-776

Proschowsky A (1930) Reproduction du Rhinechis scalaris. Bull Soc Nat d'Accl France 77:28

R Core Team (2015) R: A language and environment for statistical computing. R Foundation for Statistical Computing, Vienna, Austria. http://www.R-project.org/. Accessed 7 June 2016 Relyea RA (2002) Local population differences in phenotypic plasticity: predator-induced changes in wood frog tadpoles. Ecol Monogr 72:77-93. doi: 10.1890/00129615(2002)072[0077:LPDIPP]2.0.CO;2

Rödl T, Berger S, Romero LM, Wikelski M (2007) Tameness and stress physiology in a predatornaive island species confronted with novel predation threat. Proc R Soc Lond B Biol Sci 274:577-582. doi: 10.1098/rspb.2006.3755 
401 Salvador A (2014a) Podarcis lilfordi (Günther, 1874). In: Salvador A (coord) Reptiles, $2^{\text {a }}$ edición

402

403

404

405

406

407

408

409

410

411

412

413

414

415

416

417

418

419

420

421

422

423

424

425

426

427

revisada y aumentada. Fauna Ibérica, vol. 10, Museo Nacional de Ciencias Naturales, CSIC, Madrid, pp 556-576

Salvador A (2014b) Podarcis siculus (Rafinesque, 1810). In: Salvador A (coord) Reptiles, $2^{\mathrm{a}}$ edición revisada y aumentada. Fauna Ibérica, vol. 10, Museo Nacional de Ciencias Naturales, CSIC, Madrid, pp 602-606

Santos X (2014) Natrix maura (Linnaeus, 1758). In: Salvador A (coord) Reptiles, 2a edición revisada y aumentada. Fauna Ibérica, vol. 10, Museo Nacional de Ciencias Naturales, CSIC, Madrid, pp 820-842

Sih A, Bolnick DI, Luttbeg B, Orrock JL, Peacor SD, Pintor LM, Preisser E, Rehage JS, Vonesh JR (2010) Predator-prey naïveté, antipredator behavior, and the ecology of predator invasions. Oikos 119:610-621. doi: 10.1111/j.1600-0706.2009.18039.x

Silva-Rocha I, Salvi D, Carretero MA (2012) Genetic data reveal a multiple origin for the populations of the Italian wall lizard Podarcis sicula (Squamata: Lacertidae) introduced in the Iberian Peninsula and Balearic islands. Ital $J$ Zool 79:502-510. doi: $10.1080 / 11250003.2012 .680983$

Silva-Rocha I, Salvi D, Harris DJ, Freitas S, Davis C, Foster J, Deichsel G, Adamopoulou Ch, Carretero MA (2014) Molecular assessment of Podarcis sicula populations in Britain, Greece and Turkey reinforces a multiple-origin invasion pattern in this species. Acta Herpetol 9:253-258. doi: http://dx.doi.org/10.13128/Acta_Herpetol-14968

Silva-Rocha I, Salvi D, Sillero N, Mateo JA, Carretero MA (2015) Snakes on the Balearic Islands: an invasion tale with implications for native biodiversity conservation. PloS One 10:e0121026. doi: http://dx.doi.org/10.1371/journal.pone.0121026

Simberloff D, Martin JL, Genovesi P, Maris V, Wardle D, Aronson J, Courchamp F, Galil B, García-Berthou E, Pascal M, Pyšek P, Sousa R, Tabacchi E, Vilà M (2013) Impacts of biological invasions: what's what and the way forward. Trends Ecol Evol 28:58-66. doi: 10.1016/j.tree.2012.07.013 
428 Strauss SY, Lau JA, Carroll SP (2006) Evolutionary responses of natives to introduced species:

429

430

431

432

433

434

435

436

437

438

439

440

441

442

443

444

445

446

447

448

449 what do introductions tell us about natural communities? Ecol Lett 9:357-374. doi: 10.1111/j.1461-0248.2005.00874.x

Thoen C, Bauwens D, Verheyen RF (1986) Chemoreceptive and behavioural responses of the common lizard Lacerta vivipara to snake chemical deposits. Anim Behav 34:1805-1813. doi: 10.1016/S0003-3472(86)80266-4

Valverde JA (1967) Estructura de una comunidad de vertebrados terrestres. Monogr Est Biol Doñana 1:1-218.

Van Damme R, Castilla AM (1996) Chemosensory predator recognition in the lizard Podarcis hispanica: Effects of predation pressure relaxation. J Chem Ecol 22:13-22. doi: 10.1007/BF02040196

Van Damme R, Quick K (2001) Use of predator chemical cues by three species of lacertid lizards (Lacerta bedriagae, Podarcis tiliguerta, and Podarcis siculus). J Herpetol 35:27-36. doi: $10.2307 / 1566019$

Vermeij GJ (1994) The evolutionary interaction among species: selection, escalation, and coevolution. Annu Rev Ecol Syst 25:219-236

Vervust B, Grbac I, Van Damme R (2007) Differences in morphology, performance and behaviour between recently diverged populations of Podarcis siculus mirror differences in predation pressure. Oikos 116:1343-1352. doi: 10.1111/j.0030-1299.2007.15989.x

Vitt LJ, Cooper WE, Perera A, Pérez-Mellado V (2002) Escaping predators on vertical surfaces: Lacerta perspicillata in limestone quarries of Lithaca. Can J Zool 80:1803-1809. doi: 10.1139/z02-165 
450 TABLES

451 Table 1. Mean (range) values of each behavioural variable and results of the Friedman test $(\mathrm{df}=$ 452 3) for the experiment of Podarcis lilfordi of Aire island (Menorca, Spain) with the four scent 453 treatments (Macroprotodon mauritanicus, Rhinechis scalaris, Natrix maura, and an odourless 454 control). Only the behavioural variables that were displayed by lizards during the experiments are 455 included in the table.

\begin{tabular}{lccccll}
\hline Variable & Control & Natrix & Rhinechis & Macropr. & Chi-squared & P \\
\hline Walk latency & 43.25 & 32.75 & 38.96 & 40.79 & 2.2689 & 0.5185 \\
Walk & $(2-176)$ & $(2-142)$ & $(2-118)$ & $(4-122)$ & & \\
& 86.13 & 82.50 & 84.67 & 82.29 & 0.6176 & 0.8924 \\
Ch. sectors & $(38-138)$ & $(41-161)$ & $(23-184)$ & $(37-123)$ & & \\
& 35.21 & 34.13 & 38.00 & 31.29 & 4.6891 & 0.196 \\
TF latency & $(10-60)$ & $(13-72)$ & $(6-82)$ & $(17-43)$ & & \\
& 32.04 & 30.75 & 28.50 & 31.25 & 0.5443 & 0.9091 \\
TF & $(2-160)$ & $(5-147)$ & $(5-65)$ & $(2-120)$ & & \\
& 72.75 & 74.08 & 74.79 & 69.33 & 1.15 & 0.765 \\
Snout & $(30-126)$ & $(40-133)$ & $(5-134)$ & $(32-140)$ & & \\
& 35.62 & 33.96 & 37.21 & 30.00 & 6.383 & 0.0944 \\
Rubbing & $(9-85)$ & $(2-93)$ & $(5-72)$ & $(13-68)$ & & \\
& 50.83 & 51.87 & 52.58 & 46.63 & 1.4184 & 0.7012 \\
Stand and scr. & $(3-103)$ & $(6-108)$ & $(8-124)$ & $(9-100)$ & & \\
& 32.08 & 36.33 & 33.33 & 31.54 & 1.6835 & 0.6406 \\
Head raise & $(0-133)$ & $(5-118)$ & $(3-103)$ & $(5-93)$ & & \\
\multirow{2}{*}{ Walk time } & 32.21 & 32.38 & 38.50 & 31.75 & 5.1519 & 0.161 \\
\multirow{2}{*}{ No move } & $(16-62)$ & $(7-60)$ & $(8-67)$ & $(14-57)$ & & \\
& 273.58 & 283.04 & 296.67 & 260.46 & 2.05 & 0.5621 \\
& $(92-448)$ & $(88-481)$ & $(64-553)$ & $(145-440)$ & & \\
& 620.42 & 617.04 & 621.67 & 639.54 & 1.35 & 0.7173 \\
\hline
\end{tabular}

456 
457 Table 2. Mean (range) values of each behavioural variable and results of the Friedman test $(\mathrm{df}=$ 458 3) for the experiment of Podarcis lilfordi of Binicodrell island (Menorca, Spain) with the four 459 scent treatments (Macroprotodon mauritanicus, Rhinechis scalaris, Natrix maura, and an 460 odourless control). Only the behavioural variables that were displayed by lizards during the 461 experiments are included in the table.

\begin{tabular}{|c|c|c|c|c|c|c|}
\hline Variable & Control & Natrix & Rhinechis & Macropr. & Chi-squared & $\mathrm{P}$ \\
\hline Walk latency & $\begin{array}{c}52.92 \\
(5-128)\end{array}$ & $\begin{array}{c}61.04 \\
(10-180)\end{array}$ & $\begin{array}{c}62.83 \\
(3-368)\end{array}$ & $\begin{array}{c}48.00 \\
(6-152)\end{array}$ & 2.8109 & 0.4217 \\
\hline Walk & $\begin{array}{c}70.83 \\
(32-220)\end{array}$ & $\begin{array}{c}68.83 \\
(22-141)\end{array}$ & $\begin{array}{c}69.46 \\
(9-185)\end{array}$ & $\begin{array}{c}79.04 \\
(16-153)\end{array}$ & 2.8243 & 0.4195 \\
\hline Ch. sectors & $\begin{array}{c}28.63 \\
(14-77)\end{array}$ & $\begin{array}{l}28.54 \\
(8-56)\end{array}$ & $\begin{array}{c}30.79 \\
(5-89)\end{array}$ & $\begin{array}{l}34.63 \\
(8-63)\end{array}$ & 2.4684 & 0.481 \\
\hline TF latency & $\begin{array}{c}30.62 \\
(2-120)\end{array}$ & $\begin{array}{c}35.67 \\
(1-129)\end{array}$ & $\begin{array}{c}42.67 \\
(3-181)\end{array}$ & $\begin{array}{c}39.08 \\
(4-165)\end{array}$ & 3.153 & 0.3689 \\
\hline $\mathrm{TF}$ & $\begin{array}{c}66.25 \\
(29-126)\end{array}$ & $\begin{array}{c}69.37 \\
(31-110)\end{array}$ & $\begin{array}{c}58.13 \\
(18-121)\end{array}$ & $\begin{array}{c}69.96 \\
(27-130)\end{array}$ & 4.1667 & 0.244 \\
\hline Snout & $\begin{array}{l}20.96 \\
(1-83)\end{array}$ & $\begin{array}{l}21.46 \\
(0-54)\end{array}$ & $\begin{array}{l}22.75 \\
(4-53)\end{array}$ & $\begin{array}{l}29.00 \\
(6-59)\end{array}$ & 6.5696 & 0.0870 \\
\hline Rubbing & $\begin{array}{c}24.67 \\
(2-137)\end{array}$ & $\begin{array}{l}22.33 \\
(0-45)\end{array}$ & $\begin{array}{l}22.00 \\
(2-62)\end{array}$ & $\begin{array}{c}32.58 \\
(1-111)\end{array}$ & 6.2436 & 0.1003 \\
\hline Stand and scr. & $\begin{array}{c}17.08 \\
(0-109)\end{array}$ & $\begin{array}{l}15.33 \\
(0-50)\end{array}$ & $\begin{array}{c}12.92 \\
(0-58)\end{array}$ & $\begin{array}{l}10.58 \\
(0-31)\end{array}$ & 2.6533 & 0.4482 \\
\hline Foot shake & $\begin{array}{l}0.04 \\
(0-1)\end{array}$ & $\begin{array}{l}0.17 \\
(0-2)\end{array}$ & $\begin{array}{l}0.00 \\
(0-0)\end{array}$ & $\begin{array}{c}0.04 \\
(0-1)\end{array}$ & 6.1304 & 0.1054 \\
\hline Head raise & $\begin{array}{l}15.87 \\
(2-43)\end{array}$ & $\begin{array}{l}16.04 \\
(1-39)\end{array}$ & $\begin{array}{l}16.08 \\
(0-49)\end{array}$ & $\begin{array}{l}18.50 \\
(4-53)\end{array}$ & 1.8155 & 0.6116 \\
\hline Walk time & $\begin{array}{c}183.88 \\
(65-648)\end{array}$ & $\begin{array}{c}177.63 \\
(42-380)\end{array}$ & $\begin{array}{c}117.96 \\
(19-342)\end{array}$ & $\begin{array}{c}205.08 \\
(43-378)\end{array}$ & 2.3473 & 0.5035 \\
\hline No move & $\begin{array}{c}715.25 \\
(252-835) \\
\end{array}$ & $\begin{array}{c}726.54 \\
(520-858) \\
\end{array}$ & $\begin{array}{c}722.83 \\
(557-887) \\
\end{array}$ & $\begin{array}{c}694.87 \\
(522-856) \\
\end{array}$ & 2.8745 & 0.4114 \\
\hline
\end{tabular}


463 Table 3. Mean (range) values of each behavioural variable and results of the Friedman test $(\mathrm{df}=$ 464 3) for the experiment of Podarcis lilfordi of Colom island (Menorca, Spain) with the four scent 465 treatments (Macroprotodon mauritanicus, Rhinechis scalaris, Natrix maura, and an odourless 466 control). Only the behavioural variables that were displayed by lizards during the experiments are 467 included in the table.

\begin{tabular}{lccccll}
\hline Variable & Control & Natrix & Rhinechis & Macropr. & Chi-squared & P \\
\hline Walk latency & 25.21 & 35.96 & 33.63 & 32.33 & 3.7089 & 0.2947 \\
Walk & $(8-57)$ & $(8-151)$ & $(7-103)$ & $(9-86)$ & & \\
& 93.37 & 97.83 & 90.21 & 91.63 & 2.2911 & 0.5142 \\
Ch. sectors & $(38-206)$ & $(53-157)$ & $(36-181)$ & $(59-158)$ & & \\
& 39.92 & 43.87 & 36.62 & 40.21 & 0.5083 & 0.9175 \\
TF latency & $(16-72)$ & $(17-96)$ & $(12-68)$ & $(19-61)$ & & \\
& 24.50 & 31.50 & 28.17 & 30.58 & 2.1319 & 0.5455 \\
TF & $(2-71)$ & $(2-130)$ & $(1-123)$ & $(3-115)$ & & \\
& 89.79 & 92.96 & 84.42 & 79.08 & 6.0378 & 0.1098 \\
Snout & $(34-138)$ & $(46-172)$ & $(39-133)$ & $(35-137)$ & & \\
& 34.08 & 42.75 & 38.29 & 37.75 & 5.882 & 0.1206 \\
Rubbing & $(8-59)$ & $(13-78)$ & $(3-58)$ & $(16-69)$ & & \\
& 53.21 & 51.83 & 49.08 & 56.96 & 3.6933 & 0.2965 \\
Stand and scr. & $(3-123)$ & $(7-93)$ & $(4-74)$ & $(23-128)$ & & \\
& 37.75 & 40.96 & 41.96 & 41.88 & 6.4805 & 0.09043 \\
Head raise & $(0-167)$ & $(0-173)$ & $(0-177)$ & $(0-173)$ & & \\
& 34.08 & 36.21 & 35.58 & 33.04 & 0.4635 & 0.9268 \\
Walk time & $(16-59)$ & $(12-72)$ & $(17-63)$ & $(20-49)$ & & \\
& 271.79 & 282.71 & 276.50 & 281.96 & 0.2161 & 0.9749 \\
No move & $(106-485)$ & $(112-454)$ & $(106-472)$ & $(140-543)$ & & \\
& 641.12 & 609.63 & 626.17 & 622.63 & 1.0551 & 0.7879 \\
& $(415-794)$ & $(446-748)$ & $(428-794)$ & $(357-760)$ & & \\
\hline
\end{tabular}


469 Table 4. Mean (range) values of each behavioural variable and results of the Friedman test $(\mathrm{df}=$

470 3) for the experiment of Scelarcis perspicillata of the limestone quarry of Pedreres de S'Hostal 471 (Menorca, Spain) with the four scent treatments (Macroprotodon mauritanicus, Rhinechis 472 scalaris, Natrix maura, and an odourless control). Only the behavioural variables that were 473 displayed by lizards during the experiments are included in the table.

474

\begin{tabular}{lccccll}
\hline Variable & Control & Natrix & Rhinechis & Macropr. & Chi-squared & P \\
\hline Walk latency & 50.25 & 75.08 & 63.96 & 109.79 & 4.85 & 0.1831 \\
& $(4-315)$ & $(3-501)$ & $(3-390)$ & $(9-464)$ & & \\
Walk & 20.79 & 24.71 & 23.17 & 16.08 & 3.4068 & 0.3331 \\
& $(4-46)$ & $(8-77)$ & $(4-72)$ & $(3-33)$ & & \\
Ch. sectors & 8.83 & 10.38 & 9.96 & 7.25 & 2.1261 & 0.5467 \\
& $(3-27)$ & $(2-29)$ & $(2-26)$ & $(2-16)$ & & \\
TF latency & 57.92 & 97.75 & 61.83 & 119.67 & 4.5504 & 0.2078 \\
& $(5-318)$ & $(4-495)$ & $(4-215)$ & $(9-468)$ & & \\
TF & 11.04 & 14.58 & 11.13 & 12.17 & 1.0474 & 0.7898 \\
& $(2-31)$ & $(5-43)$ & $(2-24)$ & $(3-46)$ & & \\
Snout & 3.87 & 5.04 & 3.63 & 4.42 & 6.9324 & 0.0741 \\
& $(0-8)$ & $(1-13)$ & $(0-14)$ & $(0-26)$ & & \\
Rubbing & 6.75 & 11.04 & 6.46 & 4.04 & 5.2043 & 0.1574 \\
& $(0-37)$ & $(0-97)$ & $(0-45)$ & $(0-21)$ & & \\
Stand and scr. & 8.04 & 12.71 & 9.00 & 7.25 & 1.5 & 0.6823 \\
\multirow{2}{*}{ Foot shake } & $(0-44)$ & $(0-81)$ & $(0-31)$ & $(0-22)$ & & \\
\multirow{2}{*}{ Head raise } & 0.00 & 0.29 & 0.00 & 0.00 & 3.0 & 0.3916 \\
& $(0-0)$ & $(0-7)$ & $(0-0)$ & $(0-0)$ & & \\
Walk time & 12.50 & 14.67 & 14.54 & 9.92 & 3.4378 & 0.3289 \\
& $(3-35)$ & $(3-41)$ & $(2-47)$ & $(0-23)$ & & \\
No move & 83.79 & 99.83 & 82.17 & 62.38 & 2.4477 & 0.4848 \\
& $(10-257)$ & $(22-293)$ & $(15-235)$ & $(15-124)$ & & \\
& 816.21 & 800.17 & 817.63 & 837.63 & 2.7238 & 0.4362 \\
\hline
\end{tabular}


476 Table 5. Mean (range) values of each behavioural variable and results of the Friedman test ( $\mathrm{df}=$ 477 3) for the experiment of Podarcis siculus of the limestone quarry of Es Canutells (Menorca, Spain) 478 with the four scent treatments (Macroprotodon mauritanicus, Rhinechis scalaris, Natrix maura, 479 and an odourless control). Only the behavioural variables that were displayed by lizards during the 480 experiments are included in the table. Significant differences between treatments are marked in 481 bold.

\begin{tabular}{|c|c|c|c|c|c|c|}
\hline Variable & Control & Natrix & Rhinechis & Macropr. & Chi-squared & $\mathrm{P}$ \\
\hline Walk latency & $\begin{array}{c}59.21 \\
(5-240)\end{array}$ & $\begin{array}{c}53.67 \\
(4-175)\end{array}$ & $\begin{array}{c}53.46 \\
(5-225)\end{array}$ & $\begin{array}{c}143.21 \\
(25-352)\end{array}$ & 19.4496 & 0.0002 \\
\hline Walk & $\begin{array}{c}102.79 \\
(51-213)\end{array}$ & $\begin{array}{c}111.33 \\
(24-175)\end{array}$ & $\begin{array}{c}92.87 \\
(8-206)\end{array}$ & $\begin{array}{l}28.75 \\
(0-71)\end{array}$ & 41.0084 & $<0.0001$ \\
\hline Ch. sectors & $\begin{array}{l}37.96 \\
(8-60)\end{array}$ & $\begin{array}{l}38.58 \\
(6-63)\end{array}$ & $\begin{array}{l}35.54 \\
(4-93)\end{array}$ & $\begin{array}{l}10.75 \\
(0-28)\end{array}$ & 39.8787 & $<0.0001$ \\
\hline Slow & $\begin{array}{c}0.04 \\
(0-1)\end{array}$ & $\begin{array}{c}0.21 \\
(0-5)\end{array}$ & $\begin{array}{c}5.21 \\
(0-24)\end{array}$ & $\begin{array}{c}34.33 \\
(11-64)\end{array}$ & 60.3481 & $<0.0001$ \\
\hline TF latency & $\begin{array}{c}48.83 \\
(2-192)\end{array}$ & $\begin{array}{c}43.75 \\
(2-172)\end{array}$ & $\begin{array}{c}49.13 \\
(3-228)\end{array}$ & $\begin{array}{c}134.04 \\
(19-340)\end{array}$ & 16.4059 & 0.0009 \\
\hline $\mathrm{TF}$ & $\begin{array}{c}95.50 \\
(39-194)\end{array}$ & $\begin{array}{c}90.75 \\
(43-228)\end{array}$ & $\begin{array}{c}95.13 \\
(35-224)\end{array}$ & $\begin{array}{c}92.50 \\
(31-176)\end{array}$ & 2.1176 & 0.5484 \\
\hline Snout & $\begin{array}{l}29.88 \\
(8-60)\end{array}$ & $\begin{array}{l}29.92 \\
(3-68)\end{array}$ & $\begin{array}{l}28.33 \\
(0-50)\end{array}$ & $\begin{array}{l}17.37 \\
(3-34)\end{array}$ & 24.6992 & $<0.0001$ \\
\hline Rubbing & $\begin{array}{c}78.08 \\
(25-202)\end{array}$ & $\begin{array}{c}83.04 \\
(7-160)\end{array}$ & $\begin{array}{c}75.75 \\
(2-268)\end{array}$ & $\begin{array}{c}64.42 \\
(3-164)\end{array}$ & 4.9833 & 0.173 \\
\hline $\begin{array}{l}\text { Stand and } \\
\text { scr. }\end{array}$ & $\begin{array}{l}19.71 \\
(0-67)\end{array}$ & $\begin{array}{l}17.67 \\
(3-54)\end{array}$ & $\begin{array}{l}15.13 \\
(0-45)\end{array}$ & $\begin{array}{c}7.04 \\
(0-23)\end{array}$ & 17.9873 & 0.0004 \\
\hline Head bob & $\begin{array}{l}0.00 \\
(0-0)\end{array}$ & $\begin{array}{l}0.00 \\
(0-0)\end{array}$ & $\begin{array}{l}0.00 \\
(0-0)\end{array}$ & $\begin{array}{l}0.21 \\
(0-3)\end{array}$ & 9.0 & 0.0293 \\
\hline Head raise & $\begin{array}{c}38.71 \\
(10-75)\end{array}$ & $\begin{array}{l}35.42 \\
(6-83)\end{array}$ & $\begin{array}{l}34.46 \\
(8-72)\end{array}$ & $\begin{array}{l}24.00 \\
(0-57)\end{array}$ & 22.4359 & $<0.0001$ \\
\hline Tail waving & $\begin{array}{c}0.00 \\
(0-0)\end{array}$ & $\begin{array}{c}0.00 \\
(0-0)\end{array}$ & $\begin{array}{c}0.13 \\
(0-3)\end{array}$ & $\begin{array}{c}3.42 \\
(0-17)\end{array}$ & 37.6667 & $<0.0001$ \\
\hline Walk time & $\begin{array}{c}320.83 \\
(147-696)\end{array}$ & $\begin{array}{c}323.42 \\
(82-522)\end{array}$ & $\begin{array}{c}290.17 \\
(45-608)\end{array}$ & $\begin{array}{c}97.00 \\
(0-284)\end{array}$ & 33.65 & $<0.0001$ \\
\hline Slow time & $\begin{array}{c}0.13 \\
(0-3)\end{array}$ & $\begin{array}{c}0.00 \\
(0-0)\end{array}$ & $\begin{array}{l}14.71 \\
(0-76)\end{array}$ & $\begin{array}{c}115.38 \\
(30-245)\end{array}$ & 63.5085 & $<0.0001$ \\
\hline No move & $\begin{array}{c}576.00 \\
(204-750)\end{array}$ & $\begin{array}{c}576.17 \\
(378-818)\end{array}$ & $\begin{array}{c}591.21 \\
(178-810)\end{array}$ & $\begin{array}{c}692.21 \\
(455-827)\end{array}$ & 19.1849 & 0.0002 \\
\hline
\end{tabular}


483 Table 6. Observed values of Friedman's post-hoc paired comparisons of Friedman's test for the 484 behavioural variables in which differences between treatments were detected for the experiment 485 of Podarcis siculus of Es Canutells (Menorca, Spain) with the four scent treatments 486 (Macroprotodon mauritanicus, Rhinechis scalaris, Natrix maura, and an odourless control). The 487 critical value of Friedman's post-hoc comparisons is 29.59 for $\alpha=0.05$. Significant differences 488 are marked in bold.

\begin{tabular}{lllllll}
\hline \multirow{2}{*}{ Variable } & $\begin{array}{l}\text { Control }- \\
\text { Macropr. }\end{array}$ & $\begin{array}{l}\text { Control }- \\
\text { Natrix }\end{array}$ & $\begin{array}{l}\text { Control }- \\
\text { Rhinechis }\end{array}$ & $\begin{array}{l}\text { Macropr. }- \\
\text { Natrix }\end{array}$ & $\begin{array}{l}\text { Macropr. }- \\
\text { Rhinechis }\end{array}$ & $\begin{array}{l}\text { Natrix - } \\
\text { Rhinechis }\end{array}$ \\
\hline Walk latency & $\mathbf{3 1 . 0}$ & 2.5 & 0.5 & $\mathbf{3 3 . 5}$ & $\mathbf{3 1 . 5}$ & 2.0 \\
Walk & $\mathbf{4 9 . 5}$ & 0.0 & 16.5 & $\mathbf{4 9 . 5}$ & $\mathbf{3 3 . 0}$ & 16.5 \\
Changes among sectors & $\mathbf{4 4 . 5}$ & 7.5 & 9.0 & $\mathbf{5 2 . 0}$ & $\mathbf{3 5 . 5}$ & 16.5 \\
Slow & $\mathbf{5 2 . 5}$ & 0.5 & 17.0 & $\mathbf{5 2 . 0}$ & $\mathbf{3 5 . 5}$ & 16.5 \\
TF latency & 27.5 & 4.0 & 1.5 & $\mathbf{3 1 . 5}$ & 29.0 & 2.5 \\
Snout & $\mathbf{3 8 . 0}$ & 0.5 & 7.5 & $\mathbf{3 7 . 5}$ & $\mathbf{3 0 . 5}$ & 7.0 \\
Stand and scratching & $\mathbf{3 1 . 5}$ & 2.0 & 0.5 & 29.5 & $\mathbf{3 1 . 5}$ & 1.5 \\
Head raise & $\mathbf{4 0}$ & 10 & 20 & $\mathbf{3 0}$ & 20 & 10 \\
Tail waving & 26.5 & 0.0 & 1.5 & 26.5 & 25.0 & 1.5 \\
Walk time & $\mathbf{4 6}$ & 3 & 11 & $\mathbf{4 3}$ & $\mathbf{3 5}$ & 8 \\
Slow time & $\mathbf{5 2 . 5}$ & 1.0 & 16.5 & $\mathbf{5 3 . 5}$ & $\mathbf{3 6 . 0}$ & 17.5 \\
No move & $\mathbf{3 7}$ & 8 & 13 & 29 & 24 & 5 \\
\hline
\end{tabular}

489 


\section{FIGURE CAPTIONS}

491 Fig. 1 Studied populations, all of them from Menorca (Balearic Islands, Spain), in order of 492 increasing predation pressure: (1) Podarcis lilfordi of Colom islet, (2) P. lilfordi of Aire islet, (3) 493 P. lilfordi of Binicodrell islet, (4) Scelarcis perspicillata of Lithica, and (5) Podarcis siculus of 494 Canutells. Note that populations 1, 2 and 3 live in coastal islets while populations 4 and 5 inhabit 495 the main island of Menorca. Blank map obtained from: http://www.d496 maps.com/pays.php?num_pay=270\&lang=en.

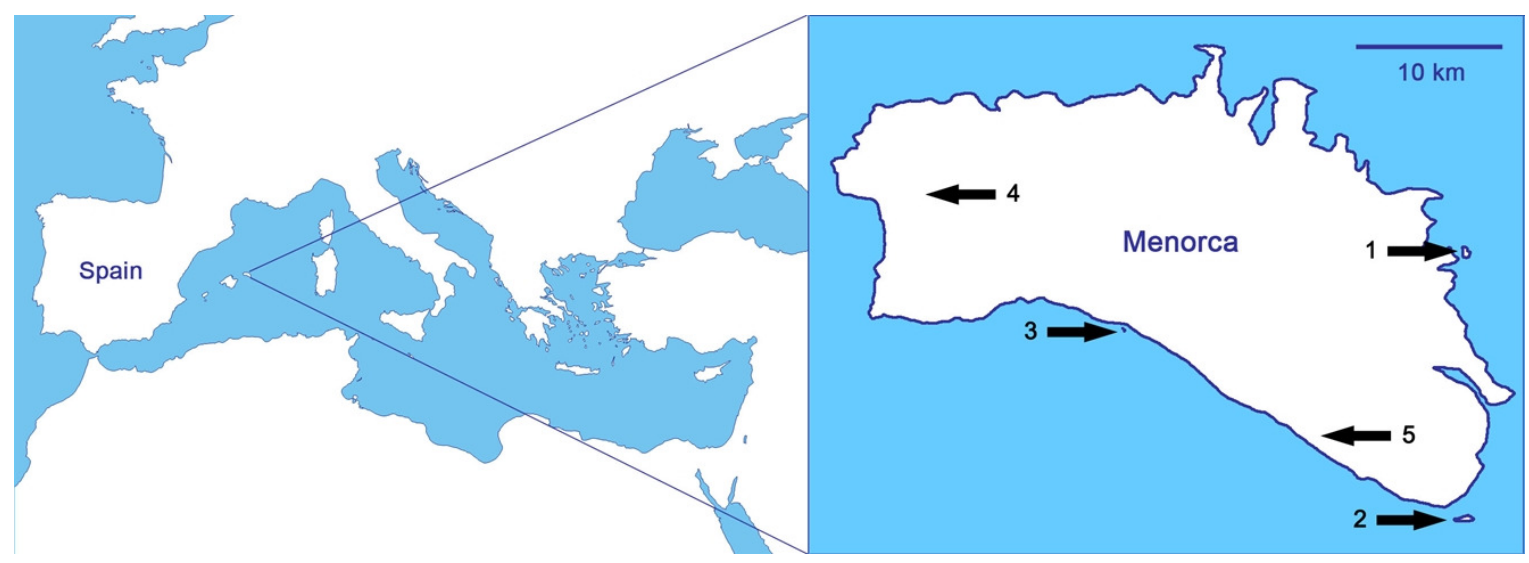


498 Fig. 2 Boxplots of the time to the first normal movement, or 'walk latency', in seconds, of Podarcis 499 siculus lizards of Es Canutells (Menorca, Spain) for the four treatments (Macroprotodon 500 mauritanicus, Rhinechis scalaris, Natrix maura, and the odourless control).

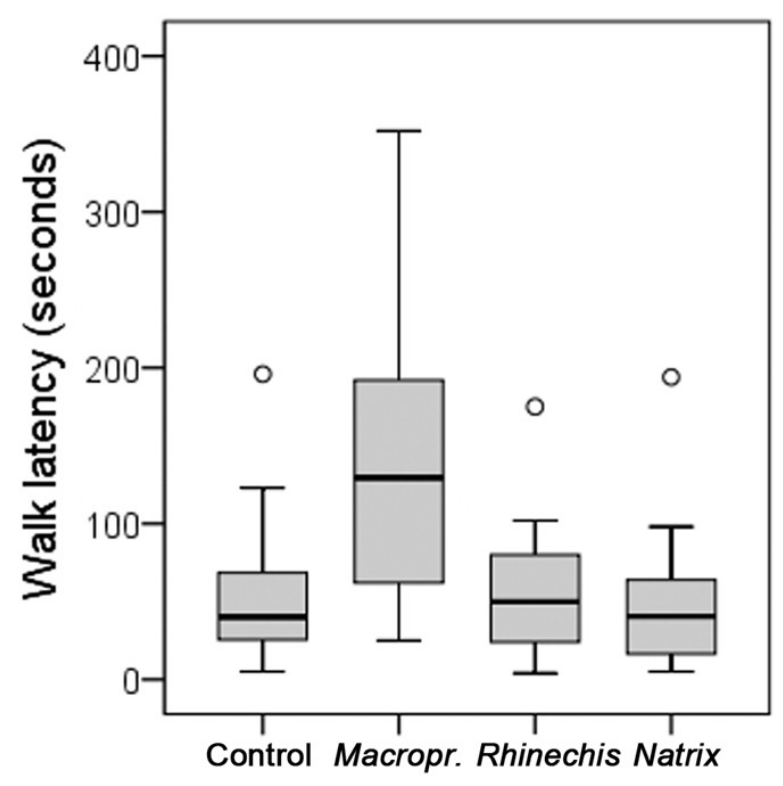

501 
502 Fig. 3 Boxplots of the absolute frequencies of normal movements, or 'walk', in number of 503 movements, of Podarcis siculus lizards of Es Canutells (Menorca, Spain) for the four treatments 504 (Macroprotodon mauritanicus, Rhinechis scalaris, Natrix maura, and the odourless control).

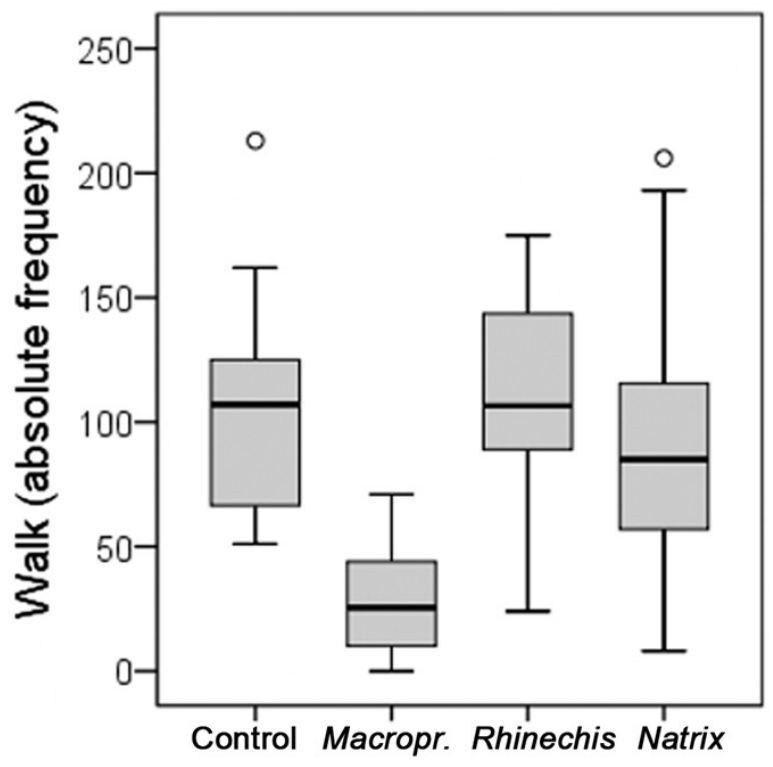

505 